\title{
Blind Technology Transfer Process from Argentina ${ }^{1}$
}

\author{
Darío Gabriel Codner ${ }^{1 *}$, Ramiro Martín Perrotta ${ }^{2}$
}

\begin{abstract}
Since the 19th century, Argentina has been characterized as an agro-exporting country reaching its peak after the First World War. Nowadays, in addition to exporting agricultural goods, Argentina has become a producer of an increasingly valuable raw material in the business world: scientific information. The accelerated increase in the production of scientific articles in high impact international journals makes Argentinean science visible all over the world. With the present study, we intend to unveil how Argentinean scientific information serves as building blocks of patents requested by foreign companies and institutions. According to the area of knowledge analyzed, we identify a differential flow of information towards the development of technologies in industrial countries. Moreover, we detected that the blind technology transfer phenomenon is a dynamic process. Herein, we present relevant evidence of scientific information flowing towards foreign technologies within 2 years after the article publication. These results suggest the need for the development of strict technology transfer policies in Argentinean universities and academic institutions in order to protect the state investment in science. Our findings highlight scientific production as a unique opportunity for economic growth and expansion of the country. This may become a fertile ground for political and economic debate.
\end{abstract}

Keywords: technology transfer; universities; patents; citations

Submitted: March 31 $1^{\text {st }}, 2018 /$ Approved: October $7^{\text {th }}, 2018$

\section{Introduction}

The novel production methods together with the new ways of generating knowledge have produced technological changes in organizations driving to the deployment of a new social era.

In production terms, innovation ${ }^{2}$ becomes a key strategy for entrepreneurial and territorial development (David \& Foray, 2002, Freeman 1982, Freeman 1987, Lundvall 1985, Nelson 1993, Nelson \& Winter, 2009, Teubal 1996). Technology developments emerge from a complex set of relationships among research centers, universities, companies, and governments. The flow of technology and information between the main actors in the process of generating knowledge promoted the creation of the National Innovation System (SNI).

In this context, knowledge and technology management has become an important factor in explaining growth and economic development. As a result, the continuous search for competitiveness prompted companies (especially multinational companies) to adopt strategies focused on innovation and cooperation to support and develop competitive advantages, particularly through partnerships with research groups under the conceptual framework of open innovation (Chesbrough, 2003). Finally, civil society has become increasingly involved in innovative processes through availability and greater access to technologies and information (Campbell \& Carayannis, 2012).

The previously described patterns have had their effects on universities. On the one hand, there was an increasing effort to develop research policies expecting to apply R\&D results (Gibbons, 2015). On the other hand, the conceptualization of the Triple Helix model
(Etzkowitz \& Leydesdorff, 1997) modified the relationship between universities and society, especially as regards the associative role with other organizations.

This led to address the complexity of technology transfer processes from novel and different conceptual approaches. For example, studies on strategy and capacities for intellectual property management, technology marketing (Bozeman, 2000, Bozeman, Fay, \& Slade, 2013, Markman, Siegel, \& Wright, 2008) or different transfer channels enforcement (Alexander \& Martin, 2013).

As a result, universities started to introduce the issue of technology transfer in their political agendas and hence, academic efforts to understand it increased drastically (mainly from Bayh-Dole law enactment in the USA in 1980 which enabled R \& D centers to appropriate and commercialize technologies). This led Universities to the development of a great diversity of institutional arrangements to meet technology transfer challenges as well as the creation of specialized units called Technology Transfer Offices (OTTs).

Nowadays, universities are involved in the process of appraising research results through mechanisms that may or may not include intellectual property records. In this regard, the topic of knowledge and technologies appropriation arises along the process of technology transfer management. In this direction, the fusion of boundaries between science and technology reveals the tensions of the traditional conception: science is a field of knowledge accumulation characterized by the tendency to publish while technology developments rely on knowledge generated by other harness intellectual property strategies (Narin \& Noma, 1985).

(1) Acknowledgements: To Gustavo Lugones, Paulina Becerra, Zelma Duchowicz and Pablo Pellegrini for their contributions in conceptual discussions and to Galo Balatti who searched for patents through an extremely accurate methodology.

(2) Innovation is the implementation of a new or highly improved product (good or service) or process, or a new marketing or organization method applied to business practices, the workplace or foreign relations. Adapted from Oslo Manual-OECD (2005).

(1) Universidad Nacional de Quilmes (UNQ), Argentina

(2) Laboratorio de Inmunopatología, Instituto de Biología y Medicina Experimental (IBYME-CONICET), Argentina, Universidad Nacional de Quilmes (UNQ), Argentina.

*Corresponding author: dcodner@unq.edu.ar 
However, valuation of research results and assessment of their technological potential require visualization and detection of scientific knowledge flow from the scientific towards the technological field. An interesting strategy to find traces of this flow is through the analysis of scientific citations in patents (Jaffe, Henderson \& Trajtenberg, 1993).

Several studies (Meyer-Krahmer \& Schmoch, 1998; Narin \& Olivastro, 1992; Noyons, van Raan, Grupp, \& Schmoch, 1994; Olivastro, 1995; van Vianen, Moed, \& van Raan, 1990) have demonstrated the presence of scientific publications in patents as an appropriate indicator to reflect science-technology relationships (Acosta, 2002, Guan \& He, 2007).

Studies of scientific citation in patents generate, among other things, information for the design of policies. For example, a South Korean study was carried out (Park \& Kang, 2009) to determine how technology production is related to Korean scientific production and how it spreads towards the industrial field. This study concluded that the spreading speed of scientific knowledge towards the technological field differs according to the area of application. Consequently, we proposed the need to adopt focused policy design approaches and strategies. For emerging technologies such as nanotechnology and biotechnology, high presence of scientific articles quoted in patents suggests that the number of citations in patents can be used as a metric of the scientific intensity of the technological field.

Van Raan (2017) presented an article reviewing the state of the art in scientific citation analysis in patents, which estimates that only $3 \%$ $-4 \%$ of scientific publications are cited in patents. This percentage increases up to a $15 \%$ when research works are made collaboratively between university and industry. In addition, the speed with which scientific knowledge flows towards technology acquires relevance. In the same work, Van Raan (op. Cit) defined "time lag" as the time between the year of article publication and the year of patent application. In this sense, the time lag heavily depends on the field of technological knowledge and can vary between 3 and 20 years. For example, the average time lag in the nanotechnology field is between 3 and 4 years (Finardi, 2011).

Besides, scientific articles cited in patents are mainly a product of public research (Carpenter, Cooper, \& Narin, 1980; Carpenter \& Narin, 1983; Narin \& Noma, op.cit). In other words, scientific research generates information flowing from the public sector to the industry. This phenomenon is especially relevant in underdeveloped countries, which do not have consolidated industrial structures capable of absorbing the scientific knowledge available.

In Argentina, scientific activities are essentially carried out in the public domain. Although research results can lead to industrial applications, there is a very low probability of local appropriation. In fact, foreign industrial companies can use the results of Argentinean scientific activity. This phenomenon has been studied and conceptualized from the point of view of technology transfer (Codner, Becerra
\& Díaz, 2012). The flow of scientific knowledge to foreign company patents has been referred to as a blind technology transfer process (BTTP). The present study provides information about how scientific knowledge is applied to the development of technology. Scientific knowledge cited in patents may be exploited in three different ways, which are: contributing to locate the technology in a field of knowledge; providing scientific evidence, or offering methodologies for the development of technological products.

While the study showed the BTTP phenomenon conducted in the field of biotechnology, this phenomenon is presumably present in other fields of knowledge as well. In this context, we propose to understand and describe the BTTP in different disciplines with the expectation of improving the design of policies to promote research and technology transfer between the public and industrial sectors.

\section{Methodology}

The present research was based empirically on the identification of scientific articles of Argentinean researchers referenced in patents applied in the United States Patent and Trademark Office (USPTO), the State Intellectual Property Office of China (SIPO) and the European Office of Patent (EPO). The measurement was made by combining available patent databases such as Espacenet, WIPO, USPTO and Google Patent.

Since 1996, the largest resources to fund R\&D projects in Argentina have been obtained through the National Agency for Scientific and Technological Promotion (AGENCIA). AGENCIA is the public organization whose mission is the promotion of scientific and innovation activities through the competitive distribution of economic resources among researchers, research groups, scientific organizations and companies (Lugones, Porta \& Codner, 2014). Obtaining financial resources from the AGENCIA represents a hallmark of prestige and quality within the Argentinean scientific community

In 2010, a study was carried out to measure the impact of AGENCIA's financing instruments on Argentinean science (Codner, 2011). This study analyzed the incidence of financing in the scientific productivity of a sample of 254 researchers (project managers) who competed for the AGENCIA's funding between 2004 and 2015. Herein the same sample of researchers was used because they represent a group of highly competitive researchers since they aspired to obtain financial resources from the most important and strict institution of research promotion.

The selection of the sample leaves out an important group of researchers who do not seek funding through the AGENCIA, so it is not completely representative of the universe of Argentinean researchers.

The researchers for the ample were selected proportionally and randomly considering the different areas of knowledge defined by the AGENCIA, with the following distribution (Table 1): 
Table 1: Researchers sample by knowledge area

\begin{tabular}{l|l}
\hline Knowledge area & Researchers amount per area \\
\hline Chemical Technology & 15 \\
Medical Sciences & 45 \\
Biological Sciences & 51 \\
Food Technology & 10 \\
Mechanical and Materials Technology & 15 \\
Mathematics and Physical Sciences & 14 \\
Earth and Hydro-atmospheric Sciences & 13 \\
Chemical Sciences & 19 \\
Agrarian, Livestock, Forestry and Fishing Technology & 54 \\
Other & 18 \\
\hline
\end{tabular}

Source: own

Regarding search methodological aspects, the criteria used were the surnames and initials, institutional affiliation and field of knowledge. In order to rule out false positives generated by very common surnames, such as Gomez, we used the abbreviation of journal name where the researchers had applied.

Another substantial aspect is that only one record per technology has been considered, that is to say, only one patent per "patent family". In addition, patents of Argentinean scientists were excluded to avoid duplication and self-citations. Once the patents referring to articles by Argentinean researchers were identified, ownership of the patent was analyzed as well as reference country and technological value applying the methodology used in previous articles (Codner, Becerra \& Diaz, op.cit).

\section{Results}

From the 254 researchers studied, 37.5\% (94 researchers) were referenced by their scientific publications on 341 patents.

Table 2 shows the distribution of patents found by discipline (according to categories used by the AGENCIA) and per researcher.

Table 2: Distribution of patents including citation per discipline and researcher

\begin{tabular}{l|l|l|l}
\hline Area & Amount of researchers per area & Patents & Patent/researcher \\
\hline Chemical Technology & 15 & 48 & 3.2 \\
Medical Sciences & 45 & 132 & 2.9 \\
Biological Sciences & 51 & 91 & 1.8 \\
Food Technology & 10 & 10 & 1.0 \\
Mechanical and Materials Technology & 15 & 10 & 0.7 \\
Mathematics and Physical Sciences & 14 & 9 & 0.6 \\
Earth and Hydro-atmospheric Sciences & 13 & 7 & 0.5 \\
Chemical Sciences & 19 & 10 & 0.5 \\
Agrarian, Livestock, Forestry and Fishing Technology & 54 & 24 & 0.4 \\
Other & 18 & 0 & 0.0 \\
\hline
\end{tabular}

On the one hand, we observed that $80 \%$ of citations in patents belonged to Chemical Technology, Medical Sciences and Biological Sciences disciplines. On the other hand, the ratio patent /researcher is a proxy which shows the BTTP with variations according to the area of knowledge analyzed. In this context, although it was not possible to determine if this happens due to intrinsic aspects of the discipline, the state of development of the medical and biological sciences in Argentina has a strong tradition. This may be an aspect revealed by the fact that the only three Nobel Prizes in science obtained by Argentineans come from these fields of knowledge. In any case, this phenomenon is an indicator of differential flow of knowledge related to disciplines and therefore, an issue to take into consideration for the designing of scientific-technological policies.

Patent analysis showed that patent owners belonged mainly to the non-academic world (see Table 3 ). This means that the private sector is actively monitoring and taking advantage of scientific data generated in Argentina. Interestingly, a high percentage of applicants were from foreign academic institutions, which showed the important role played by the TTOs from main worldwide academic institutions.

(3) A set of data consisting of publications of equivalent patents, and refer to the same invention. The same patent can be requested in different regional offices (USPTO, SIPO, $\mathrm{EPO})$ presenting the same information in each of them. 
Table 3: Patent owners distribution

\begin{tabular}{|c|c|}
\hline Patent owner & Sample distribution \\
\hline Firms & $47 \%$ \\
\hline Individuals & $10 \%$ \\
\hline TTOs & $43 \%$ \\
\hline
\end{tabular}

We studied the origin of patents that incorporated citations of scientific articles produced in Argentina. As table 4 shows, these patents were applied by firms and TTOs of developed world countries. This feature indicates that BTTP is a process which frames and reinforces the global economic concentration. It is important to highlight that no patents of Argentinean companies were found, which shows the industrial gap between Argentina and other countries.

Table 4: Patent owner countries

\begin{tabular}{c|c}
\hline Country & Sample distribution \\
\hline United States & $49 \%$ \\
Great Britain & $8 \%$ \\
China & $7 \%$ \\
Germany & $7 \%$ \\
France & $5 \%$ \\
Canada & $4 \%$ \\
Others ${ }^{1}$ & $29 \%$ \\
\hline \multicolumn{2}{c}{ Source: own }
\end{tabular}

As illustrated in Figure 1, Argentine scientific information flows mainly to foreign patents ${ }^{4}$ belonging to leading multinational companies such as Monsanto, Du Pont, BASF and leading educational and scientific institutions such MIT, the University of Manchester, Max Planck Society and the University of Beijing.

Fig 1. Major countries citing articles from Argentinean researchers in their patents



Source: own
Previous works (Codner, Becerra \& Diaz, op cit) showed that citations of Argentinean scientific articles present a different meaning according to the way in which they are referenced in patents. In this study, we determined that scientific articles in patents are used to support or validate protected technologies in three different ways: being part of the technology state of the art (identifies the field of knowledge in which that technology intervenes); as scientific evidence (references to previous research results made by R \& D groups); or as a methodology (necessary to carry out the technology addressed). Scientific evidence and the development of methodologies represent the real technological appraisal mechanisms of the scientific article. Figure 2 shows the distribution of scientific articles according to the previously mentioned categories.

From the referenced articles, $44 \%$ were used as scientific evidence or methodology. These items represented time and money saving for the patented technology developers. In this sense, it can be assumed that if patent owners had lacked access to these studies, they should have had to carry out experiments or develop relevant methodologies to support their inventions. Because information categorized as state of the art does not necessarily represent a source of inspiration or an intrinsically technological value to the patent, it was decided to exclude this group of patents from subsequent analyzes.

Fig 2. Technological value provided by the paper

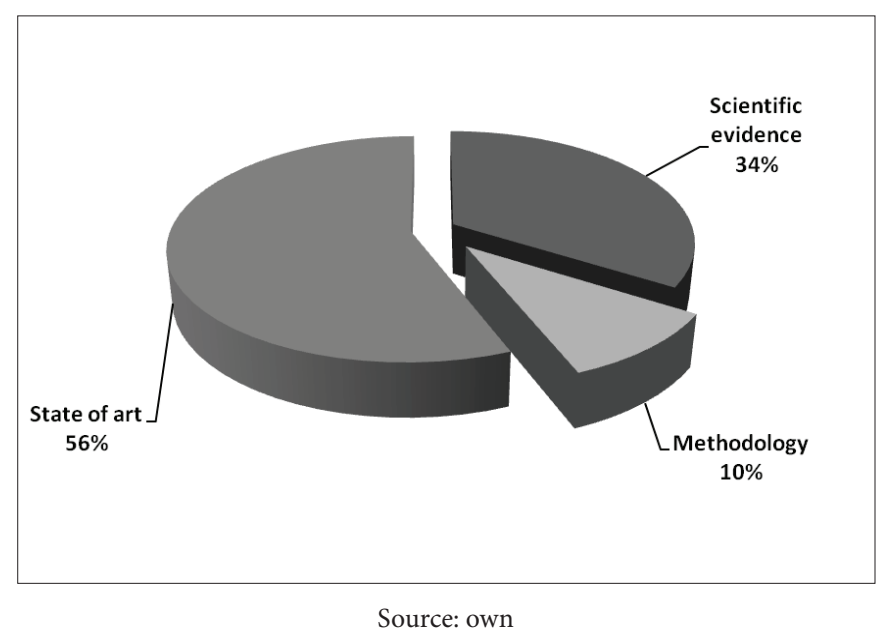

In agreement with the work of Park \& Nang (op.cit), we confirmed the existence of differences among technological fields regarding the intensity of scientific articles citation in patents (see Table 5). Data indicate that the BTTP from Argentina is strongly concentrated in the field of biomedicine and biological sciences.

(4) Some of the patents owners are: Colgate-Palmolive Company; Antioxidant Pharmaceuticals Corp; Monsanto; E.I. Du Pont De Nemours And Company; Gema Diagnostics, Inc; Synthonics, Inc; Hershey Foods Corporation; Kraft Foods R\&D, Inc; Apicore, Llc; Abbott Laboratories; Ford Global Technologies, Llc; Aurora Algae, Inc; Dyax Corp; Promega Corporation; Regeneron Pharmaceuticals, Inc; Agilent Technologies INC; Gilead Sciences Corp; Amura Therapeutics Limited; Galecto Biotech AB; Xention Ltd, Fresenius Kabi Deutschland GmbH; Nano-X Gmbh; Immatics Biotechnologies GmbH; BASF, Shanghai Lawring Biomedical Co., Ltd; China National Petroleum Corp; Tat Life Sciences Ltd; Micro Technology Co; Ltd, Agirx Limited; Massachusetts Institute Of Technology (MIT); Baylor University; Syracuse University; Boston Biomedical Research Institute; Northwestern University; Yale University; Washington University;Boston University; University of Pennsylvania; Mayo Foundation for Medical Education and Research; University Of Manchester; The University Of Warwick; The University Of Bristol; Max Planck Society for the Advancement of Science; Charité- UniversityMedicine Berlin; Dusseldorf University; University of Ulm; University of Wurzburg; Nanjing University; Binzhou Medical College; Jiaotong University; Beijing University; Wuhan University, among others. 
Table 5: Paper technological contribution per discipline

\begin{tabular}{|c|c|c|}
\hline Área & Methodology & Scientific Evidence \\
\hline Chemical Technology & 7 & 6 \\
\hline Medical Sciences & 5 & 56 \\
\hline Biological Sciences & 15 & 31 \\
\hline Food Technology & 1 & 3 \\
\hline Mechanical and Materials Technology & 1 & 5 \\
\hline Mathematics and Physical Sciences & 0 & 5 \\
\hline Earth and Hydro-atmospheric Sciences & 0 & 7 \\
\hline Chemical Sciences & 2 & 1 \\
\hline Agrarian, Livestock, Forestry and Fishing Technology & 2 & 8 \\
\hline
\end{tabular}

Source: own

Finally, together with the technological appraisal mechanisms of the scientific articles, "time lag" is a relevant aspect to understand and describe the BTTP process and its impact. Shorter time lag records indicate closer time proximity between the scientific result and the technological use.

More than $40 \%$ of the articles used as methodology or scientific evidence presented a time lag within 2 years after article publication (see Figure 3). This showed, on the one hand, an important acceleration in the use of research results and, on the other hand, the intrinsic value of the research results carried out by Argentinean scientists.

Fig 3. Time between scientific article publication and patent application (time lag) according to technological value

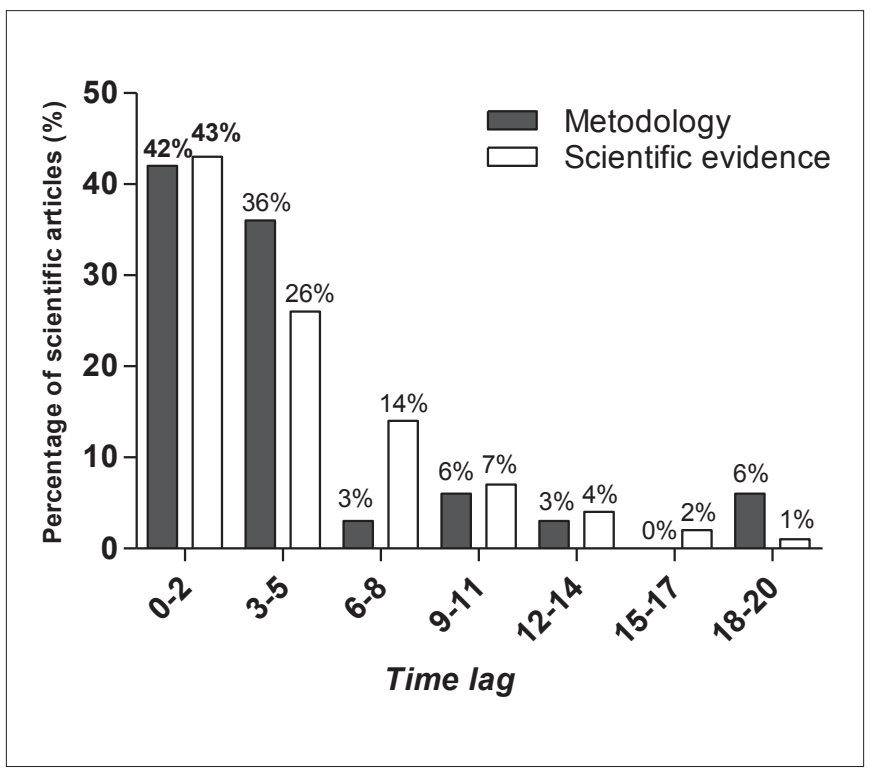

Source: own

\section{Conclusions}

The present work aims at contributing to the understanding of blind technology transfer process in Argentina by analyzing a pool of foreign patents which incorporated citations from Argentinean researchers specialized in various fields of knowledge.
In the first place, our results confirm that BTTP is an extended phenomenon in many fields of research. This phenomenon is especially relevant in the field of biomedical science, due to the high concentration of articles cited in foreign patents. This is an indicator of the quality and quantity of Argentinean scientific research in this field.

Secondly, scientific knowledge flows mainly to technologies developed by companies and institutions in developed countries (especially the United States, Great Britain, China, and Germany); and, to a lesser extent, it flows to emerging economies and developing countries, without any Argentinean company being among the patents that make reference to Argentinean scientists' publications. This feature points out that BTTP is a phenomenon which denotes the process of industrial capacities concentration of a small group of countries, replicating the process of global economic concentration. Moreover, the significant number of patents in the academic sector also highlights the influence of TTOs as a tool for promoting technological development.

Furthermore, the study confirmed that both scientific evidence and methodology development are technological appraisal mechanisms of scientific articles and they can be used as proxy indicators of the impact of science on technology.

Interestingly, we also found that information spread by scientific journals rapidly flows (within two years after publication) to technology. This work presented the first evidence of the existence of a time lag shorter than 2 years, which reinforces the idea of using time lag as an indicator of the impact of science on technology.

To conclude, this research provided elements to strategically consider the analysis of the technological value of the scientific articles cited in patents to design harmonized research policies as well as technology transfer policies focused on both field of knowledge and industrial development policies.

Furthermore, the analysis of citations in patents allowed us to know the technological relevance of scientific publications with political implications by making visible the traces of the flow of knowledge.

Finally, this paper brings into question the center-periphery relationship between countries since it emphasizes the need to reflect on the 
efforts to promote scientific development and local industrial capacities in order to absorb the results from public research. That is to say, while promoting science is an action which a priori capitalizes the underdeveloped countries, the lack of industrial development expectations determines the possibility of the local absorption of efforts. In this way, the underdeveloped countries will continue to subsidize developed countries industry through their public investments in science which, in turn, will reinforce the economic gap between countries.

\section{References}

Acosta, M. C., D. (2002). Las relaciones ciencia-tecnología en España. Evidencias a partir de las citas cientificas en patentes. Economía industrial, 346, 27-46.

Allen, A., Martin, D (2013). "Intermediaries for open innovation: A competence-based comparison of knowledge transfer offices practices." Technological Forecasting and Social Change 80 (1):38-49. doi: 10.1016/j.techfore.2012.07.013.

Bozeman, B. (2000). Technology Transfer and Public Policy: a Review of Research and Theory. Research Policy, 29(4-5), 627-655.

Bozeman, B., Fay, D., \& Slade, C. P. (2013). Research collaboration in universities and academic entrepreneurship: the-state-of-the-art. The Journal of Technology Transfer, 38.

Campbell, D. F. J., \& Carayannis, E. G. (2012). Epistemic Governance in Higher Education: Quality Enhancement of Universities for Development: Springer New York.

Carpenter, M.P., Cooper, M., \& Narin, F. (1980). The linkage between basic research literature and patents. Research Management, 13(2), $30-35$.

Carpenter, M.P., \& Narin, F. (1983). Validation study: Patent citations as indicators of science and foreign dependence. World Patent Information, 5(3), 180-185.

Codner, D. G., Becerra, P., \& Díaz, A. (2012). Blind Technology Transfer or Technological Knowledge Leakage: a Case Study from the South. Journal of technology management \& innovation, 7, 184195.

Codner D. (2011). "Alcance, resultados e impactos del FONCYT entre 2006 y 2010”. Codner D. en Investigación científica e innovación tecnológica en Argentina: impacto de los fondos de la Agencia Nacional de Promoción Científica y Tecnológica. Universidad Nacional de Quilmes. ISBN: 978-987-558-234-7

Chesbrough, H. W. (2003). Open Innovation: The New Imperative for Creating and Profiting from Technology: Harvard Business School Press.

David, P. A., \& Foray, D. (2002). An introduction to the economy of the knowledge society. International Social Science Journal, 54(171), 9-23. doi: 10.1111/1468-2451.00355
Etzkowitz, H., \& Leydesdorff, L. A. (1997). Universities and the Global Knowledge Economy: A Triple Helix of University-industry-government Relations: Pinter.

Finardi, U. (2011). Time relations between scientific production and patenting of knowledge: The case of nanotechnologies. Scientometrics, 89(1), 37-50.

Freeman, C. (1982). Technological infrastructure and international competitiveness. Paper presented at the OECD Global Forum on Development.

Freeman, C. (1987). Technology, policy, and economic performance: lessons from Japan: Pinter Publishers.

Gibbons, M. (2015). La nueva producción del conocimiento La dinámica de la ciencia y la investigación en las sociedades contemporáneas (Vol. 28).

Guan, J., \& He, Y. (2007). Patent-bibliometric analysis on the Chinese science - technology linkages. Scientometrics, 72(3), 403-425. doi: 10.1007/s11192-007-1741-1

Jaffe, A. B., M. Trajtenberg, and R. Henderson, “Geographic Localization of Knowledge Spillovers as Evidenced by Patent Citations," The Quarterly Journal of Economics 108:3 (1993), 577-598.

Lugones G, Porta F \& Codner D.(2014). Insights into the Impact of BID’s Technology Modernization Program on Argentina's STI. Chapter 3. in Dutrenit and G. Crespi (eds.), Science, Technology and Innovation Policies for Development, ISBN: 978-3-319-04107-0 (Print) 978-3-319-04108-7 (Online). doi: 10.1007/978-3-319-04108-7_3

Lundvall, B. Å. (1985). Product Innovation and User-producer Interaction: Aalborg University Press.

Markman, G. D., Siegel, D. S., \& Wright, M. (2008). Research and Technology Commercialization. Journal of Management Studies, 45(8), 1401-1423. doi: 10.1111/j.1467-6486.2008.00803.x

Meyer-Krahmer, F., \& Schmoch, U. (1998). Science-based technologies: university-industry interactions in four fields. Research Policy, 27(8), 835-851.

Narin, F., \& Noma, E. (1985). Is technology becoming science? Scientometrics, 7(3), 369-381. doi: 10.1007/BF02017155

Narin, F., \& Olivastro, D. (1992). Status report: Linkage between technology and science. Research Policy, 21(3), 237-249. doi: 10.1016/0048-7333(92)90018-Y

Narin, F., \& Olivastro, D. (1998). The linkage between patents and papers: An interim EPO/US comparison. Scientometrics, 41(1), 51-59. doi: $10.1007 / \mathrm{BF} 02457966$

Narin, F., \& Noma, E. (1985). Is technology becoming science? Scientometrics, 7(3-6), 369-381. 
Narin, F., Rosen, M., \& Olivastro, D. (1989). Patent citation analysis: New validation studies and linkage statistics. In A.F.J. van Raan, A.J. Nederhoff, \& H.F. Moed (Eds.), Science and Technology Indicators: Their Use in Science Policy and their Role in Science Studies. Leiden: DSWO Press.

Nelson, R. R. (1993). National Innovation Systems: A Comparative Analysis: Oxford University Press.

Nelson, R. R., \& Winter, S. G. (2009). An Evolutionary Theory of Economic Change: Harvard University Press.

Noyons, E. C. M., van Raan, A. F. J., Grupp, H., \& Schmoch, U. (1994). Exploring the science and technology interface: inventor-author relations in laser medicine research. Research Policy, 23(4), 443-457.

Olivastro, F. N. K. H. D. (1995). The linkage between agency-supported Research and patented industrial technology. Research Evaluation, 5(3), 183-187.

Park, H. W., \& Kang, J. (2009). Patterns of scientific and technological knowledge flows based on scientific papers and patents. Scientometrics, 81(3), 811. doi: 10.1007/s11192-008-2224-3
Rama, C. (2006). La Tercera Reforma de la Educación Superior en América Latina y el Caribe: masificación, regulaciones e internacionalización. IESALC, Informe sobre la educación superior en América Latina y el Caribe, 2005, 11-18.

Teubal, M. (1996). R\&D and technology policy in NICs as learning processes. World Development, 24(3), 449-460. doi: 10.1016/0305750X(95)00156-7

van Looy, B., Debackere, K., Callaert, J., Tijssen, R., \& van Leeuwen, T. (2006). Scientific capabilities and technological performance: An exploration of emerging industrial relevant research domains. Scientometrics, 66(2), 295-310.

van Raan A. (2017). Patent Citations Analysis and Its Value in Research Evaluation: A Review and a New Approach to Map Technology-relevant Research. Vol. 2 No. 1, 2017. pp 13-50. DOI: 10.1515/ jdis-2017-0002

van Vianen, B. G., Moed, H. F., \& van Raan, A. F. J. (1990). An exploration of the science base of recent technology. Research Policy, 19(1), 61-81. doi: 10.1016/0048-7333(90)90034-4 